\title{
Hall for Workshop of Meta-Synthetic Engineering for the Demonstration of Airborne Equipment Development
}

\author{
FU Xin Hua \\ Air Force Airborne Academy, Guilin, Guangxi, 541003, China \\ fuxinhua_003@163.com
}

Keywords: airborne equipment, demonstration, hall for workshop, technical framework, model

\begin{abstract}
Since conventional methods cannot resolve the complex problem of airborne equipment development, the Hall for Workshop of Meta-Synthetic Engineering for the demonstration of airborne equipment development is built in this paper to improve the scientificity of the demonstration of airborne equipment development, with application of the methodology "Hall for Workshop of Meta-Synthetic Engineering (HWME)" proposed by Qian Xuesen to handle large-scale complex system problems. The HWME for the demonstration of airborne equipment development integrates expert groups, data plus relevant information, and computer simulation, as well as scientific theories of relevant fields and man experience plus knowledge. As a combination of charrette and simulation experiment, it provides a hierarchical, open and distributed interactive environment for the demonstration of airborne equipment development. This paper proposes the architecture of the HWME for the demonstration of airborne equipment development, describes flexible design methods for the technical framework, and analyzes the realization of synthetic integration for the demonstration of airborne equipment development. It is of theoretical value to the realization of the HWME for the demonstration of airborne equipment development.
\end{abstract}

\section{Introduction}

The airborne weapon and equipment system, as a large-scale complex system, involves knowledge of various layers, fields, and types. In addition, airborne equipment has to meet three requirements of aerial platform loading, aerial delivery and ground combat ${ }^{[1]}$. This implies the complexity and particularity of airborne equipment development. Practice indicates that it is an inexorable trend to resolve weapon and equipment development with the HWME ${ }^{[2-3]}$. Therefore, this paper builds the HWME for the demonstration of airborne equipment development to improve the scientificity of the demonstration of airborne equipment development, with application of the methodology "Hall for Workshop of Meta-Synthetic Engineering" proposed by Qian Xuesen to handle large-scale complex system problems.

\section{Architecture}

The HWME for the demonstration of airborne equipment development integrates the expert system, knowledge system, and machine system, as well as charrette and simulation experiment. It provides a hierarchical, open and distributed interactive environment for the demonstration of airborne equipment development. See Fig. 1 for its architecture. It is essentially a highly intelligent man-machine integration system, which integrates modern high \& new technologies based on computer with the expert system ${ }^{[4]}$. Based on software and hardware environment of the hall for workshop and supported by the knowledge system and the machine system, the expert system provides decision-making consulting to command organs and relevant decision makers by holding demonstration and workshops in methods of synthetic analysis, quantitative computation, simulation experiment, and assessment validation, with consideration of various problems in airborne equipment building and evolution, military struggle requirements as well as technical and economic conditions. The HWME for the demonstration of airborne equipment development improves scientificity and efficiency of demonstration by the integration of the theory of various subjects and expert experience 
and knowledge as well as man-centered man-machine integration to realize a synthetic integration of information and knowledge.

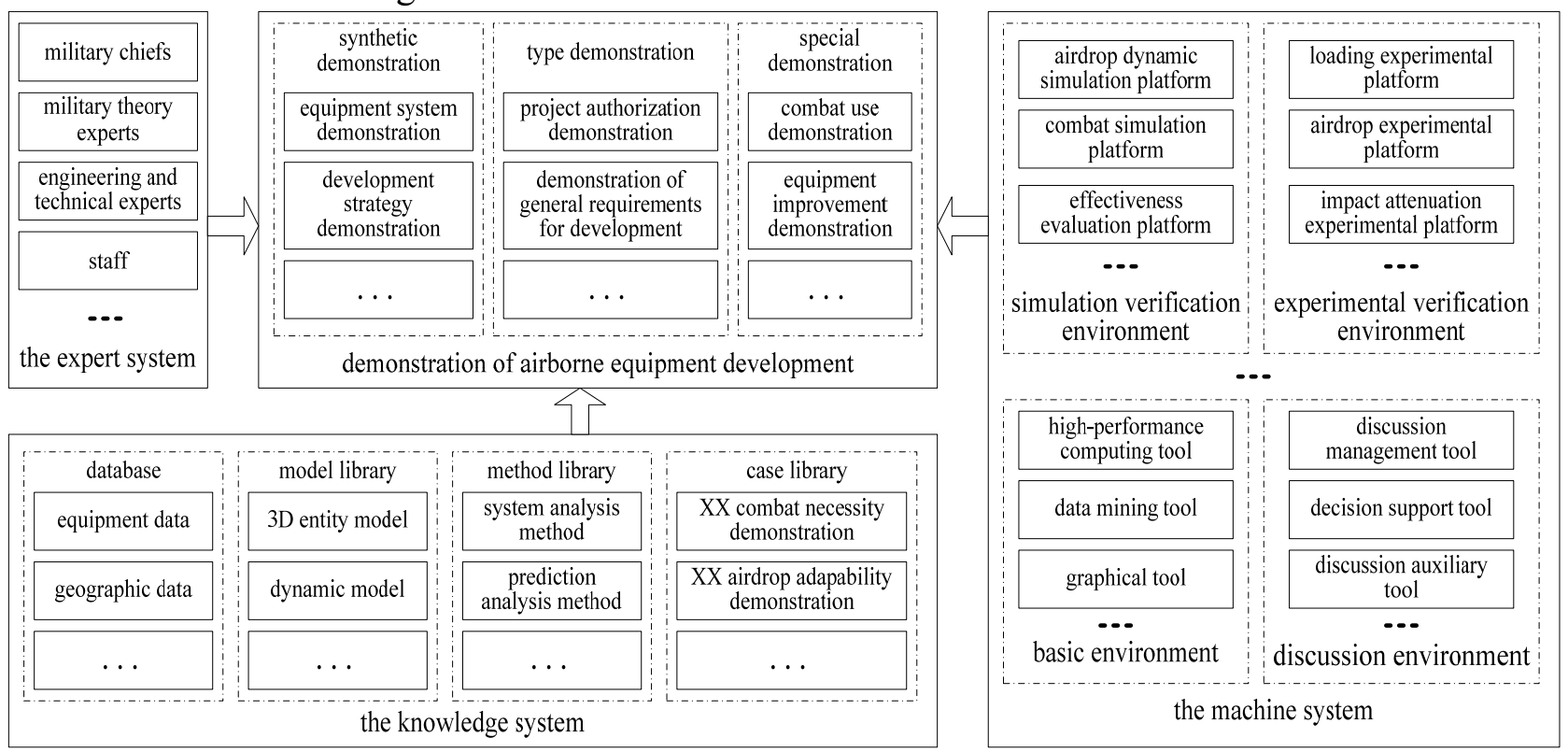

Fig. 1 Architecture of HWME for the demonstration of Airborne Equipment Development

The expert system is the main body as well as a core and decisive element of the hall for workshop. It consists of various personnel attending workshops, such as military chiefs, military theory experts, engineering and technical experts, staff, and equipment users involved in the entire life circle of airborne equipment. The expert system is a dynamic group which can be optimized and adjusted according to demonstration task types to improve demonstration quality. Workshops cover topics involved in airborne equipment development, such as synthetic demonstration, type demonstration, and special demonstration. The functions of the expert system are embodied in "dynamism" of man such as through and experience. Expert groups have "man-man", "man-machine" and "man-machine to man-machine" communication and workshops as well as multi-way thinking and re-grouping to generate expert collective intelligence ${ }^{[5]}$.

The machine system, as the operation and support platform for the hall for workshop, consists of computer software and hardware used by experts as well as those servers, tools, and experimental platforms providing various services to the entire expert group. These include three categories: First, various types of simulation verification environment that support airdrop dynamic simulation, combat simulation, and effectiveness evaluation for airborne equipment; second, various types of experimental verification environment that support airborne equipment loading experiments, airdrop experiments, impact attenuation experiments, and so on; third, various computing, data processing, management, coordinating, and workshop tools. The function of the machine system is to support simulation experiments, decision support, and workshop process. With information processing, data analysis, and simulation computation, the machine system assists research by the expert group and meets their quantitative analysis demands such as multi-angle, multi-layer, yet multi-resolution simulation, analysis and computation so as to improve demonstration efficiency ${ }^{[5]}$.

The knowledge system, as the workshop foundation of the hall for workshop, consists of various types of knowledge such as domain knowledge relevant to the demonstration of airborne equipment development and problem solving knowledge. These include various types of databases, model libraries, method libraries, and case libraries. The expert system and the machine system are the carriers of the knowledge system. The function of the knowledge system is to provide predecessor or previous experience knowledge, domain knowledge, and real-time intelligence knowledge. It integrates the above mentioned with relevant simulation experiment knowledge as well as collides them with expert collective and intrinsic knowledge to generate new knowledge so as to provide workshop foundation and reference mode to the demonstration of airborne equipment development. 


\section{Flexible Design of the Technical Framework}

As per functional requirements, the technical framework of the HWME for the demonstration of airborne equipment development consists of the client, application layer, service layer, and resource layer from top to bottom (See Fig.2).

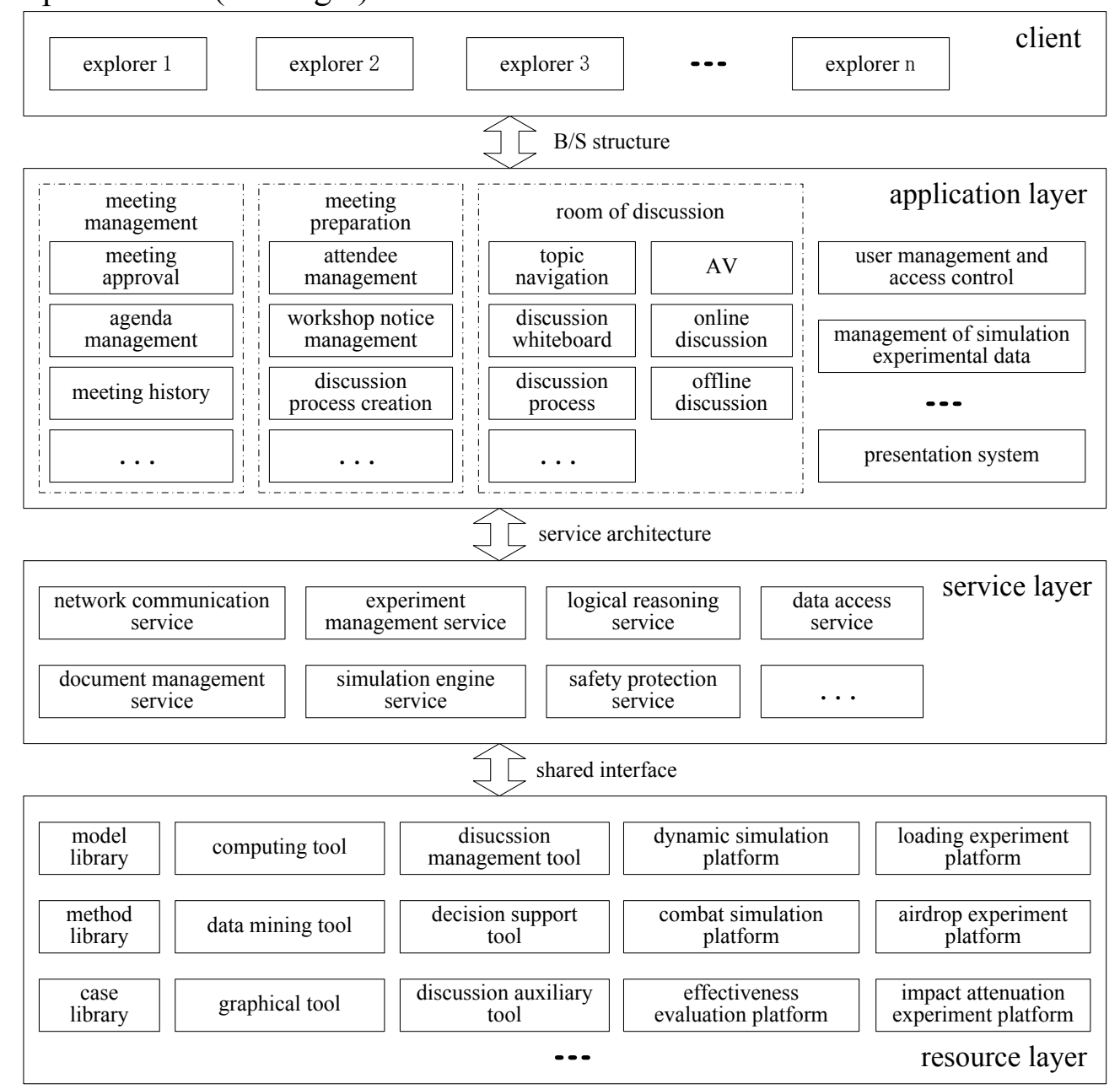

Fig. 2 Technical Framework of HWME for the Demonstration of Airborne Equipment Development

The hall for workshop adopts the B/S structure. It supports synchronous and asynchronous discussion between distributed experts. At the client, invited experts use Internet Explorer as the interface to explore the internal information of the hall for workshop. They can access and call resources, tools and so on in the platform according to their privileges.

The application layer is the man-machine interactive interface of the hall for workshop. It closely combines system related elements and has meta-synthetic engineering of information and data resources using the WWW mechanism of the Internet ${ }^{[6]}$. The application layer, which is responsible for user management, access control, data management, and meeting management, effectively combines experts and resources via the hall for workshop. According to the requirements of demonstration tasks, the application layer can invite different experts to discussion. The invited experts discuss the problem in various discussion methods provided by the hall for workshop, with a full presentation of their experience and knowledge as well as unleashing of their creativity. As per discussion requirements, experts can also call relevant resources provided by the platform autonomously to help themselves form views and perspectives.

The service layer provides various runtime support services to the application layer based on the service architecture, such as network communication, document management, simulation engine, logical reasoning, and data access. As a basic element of functional modules forming the hall for workshop, the service layer can realize use and management of the resource layer via shared interfaces. The service layer realizes integration of the expert system, models, the simulation experimental system, and so on with the distributed object technology. 
The resource layer, as the basis support of the entire HWME, consists of various resources supporting discussion, such as databases of models / methods / cases, data mining / decision support / computation tools, and simulation experimental platforms supporting dynamic simulation / combat simulation / loading experiments / airdrop experiments.

\section{Realization of Synthetic Integration}

Without loss of generality, Fig.3 illustrates the realization of meta-synthetic engineering for the demonstration of airborne equipment development. Utilizing the knowledge system stored on machine and the high-speed network based machine system, experts such as military experts, engineering and technical experts, inference experts, and computer experts realize meta-synthetic engineering by searching and assembling relevant data, knowledge, and tools, having democratic workshops, and stimulating collective intelligence according to the problem to be demonstrated ${ }^{[7]}$.

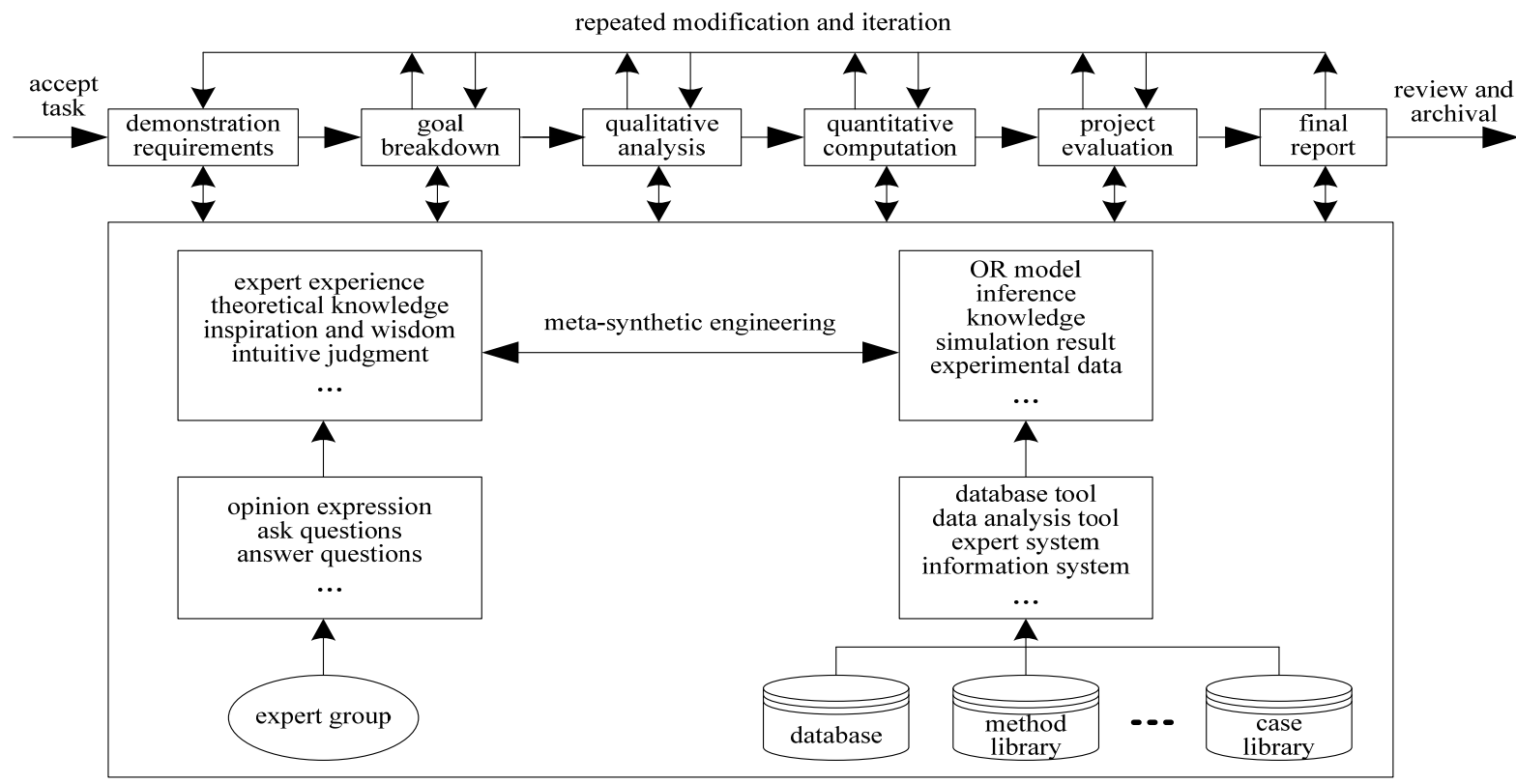

Fig. 3 Realization of Meta-Synthetic Engineering for the

Demonstration of Airborne Equipment Development

1) Accept demonstration tasks from a user. According to characteristics of airborne equipment, specify demonstration type and requirements, determine the demonstration workshop process, invite experts, and then define their roles, privilege, tasks and division of labor.

2) According to demonstration tasks and requirements, the user, military experts, engineering and technical experts, inference experts, and computer experts break down demonstration tasks and goals, analyze decision-making goals of sub-tasks, study problem features of sub-tasks, clarify constraint conditions of sub-tasks, and specify relevant key technologies using the knowledge system and the machine system.

3) As per demonstration tasks and goals, invited experts pointedly collect and retrieve demonstration related knowledge, methods, models, cases, and intelligence from the hall for workshop or relevant external platforms. Then they analyze and discuss the problem to be demonstrated according to their experience and intuition so as to have an empirical hypothesis and qualitative judgment of the problem to be demonstrated as well as have early insights into the problems related to the demonstration of airborne equipment development.

4) The invited experts have group discussion on the problem to be demonstrated based on the hall for workshop. With their experience and visual thinking, they offer solutions by means of presenting personal opinions, asking questions, and so on. Then they gradually quantify the problem and have a quantitative knowledge of it by integrating domain knowledge and predecessor experience, utilizing relevant auxiliary tools, using group opinion statistical and integration methods, as well as having charrette and relevant simulation experiments plus verification. 
5) According to quantitative or semi-quantitative analysis results, blend opinions of all groups, build a computer partial or global model for the problem using conceptual system structural fusion tools, cross-cutting relation analysis tools, and interdisciplinary model integration tools. Generate an equipment development project in group decision-making methods such as the brainstorming method, the nominal group technique, Delphi Method, and AHP (analytic hierarchy process).

6) Convene relevant experts and users. Evaluate the project with a proper quantitative evaluation tool according to the project evaluation index system and demonstration goals. Have multiple modification and repeated iteration until the project meets demonstration requirements. Complete the final report and archive it after review.

Meta-synthetic engineering for the demonstration of airborne equipment development is highly complex. It is a circulatory and spiral process which requires multi-layer feedback. The final resolution of the problem relies on the integration of expert discussion opinions and the project. The conclusion will be formed after computer processing as well ascontinuous modification and iteration..

\section{Summary}

This paper not only proposes the architecture of the HWME for the demonstration of airborne equipment development but also describes flexible design methods for the technical framework and the realization of synthetic demonstration integration. It is of theoretical value to the realization of the HWME for the demonstration of airborne equipment development. The establishment of the HWME for the demonstration of airborne equipment development is a synthetic complex engineering system, in which key technologies, such as standards system and meta-synthetic engineering model for expert opinions, require deep dive in the future.

\section{References}

[1] ZHANG Songbao, XIU Baoxin, ZENG Qianteng, YANG Zun. Research on Simulation Experiment with Development of Airbome Weapons and Equipment [J]. Fire Control\& Command Control, 2014.12, 39(12):167 170.

[2] ZHOU Jian, ZHU Yaoqin, TANG Weiqing. Weapon equipment system synthesis in hall for workshop of meta-synthetic engineering [J]. Systems Engineering Theory \& Practice, 2010.8, 30(8): 1492 1499.

[3] YU Tonggang, YU Hongmin, GAO Song. Study on Workshop Hall for Metasynthetic Engineering of the Development of Weaponry and Equipment[J]. Journal of Academy of Armored Force Engineering, 2007.8, 21(4):9 12.

[4] ZHANG Dawei, LV Ruiqiang, SONG Yongde. Study on Workshop Hall for Metasynthetic Engineering of the four-station Equipment[J]. Journal of Xuzhou Air Force College, 2011.9, 22(5):46 49.

[5] YI Bensheng. Study on Workshop Hall for Metasynthetic Engineering of Military Theory Innovation[J]. Military Operations Research and Systems Engineering, 2011.12, 25(4):15 19.

[6] HAN Xianglan, WU Huizhong, CHEN Shenglei, WAN Jian ming. Hall for Workshop of Metx synthetic Engineering for Demonstration of Weapon and Equipment[J]. Journal of NanJing University of Science and Technology, 2005.8, 29(4):446 450.

[7] ZHANG Xunli, GAO Guiqing, YU Kundong, LI Yongxiang. The Development of Confront Drilling Training System Based on HWME[J]. Acta Armamentarii of SiChuang, 2013.8, 34(8): $111 \sim 114$. 